\title{
Author Correction: Iron restriction inside macrophages regulates pulmonary host defense against Rhizopus species
}

\author{
Angeliki M. Andrianaki ${ }^{1}$, Irene Kyrmizi ${ }^{1,2}$, Kalliopi Thanopoulou ${ }^{3}$, Clara Baldin $^{4}$, Elias Drakos ${ }^{1}$, \\ Sameh S.M. Soliman ${ }^{5}$, Amol C. Shetty ${ }^{6}$, Carrie McCracken ${ }^{6}$, Tonia Akoumianaki ${ }^{1}$, Kostas Stylianou$^{1}$, \\ Petros loannou (10 1, Charalampos Pontikoglou', Helen A. Papadaki ${ }^{1}$, Maria Tzardi ${ }^{1}$, Valerie Belle ${ }^{7}$, \\ Emilien Etienne ${ }^{7}$, Anne Beauvais ${ }^{8}$, George Samonis ${ }^{1}$, Dimitrios P. Kontoyiannis ${ }^{9}$, Evangelos Andreakos ${ }^{3}$, \\ Vincent M. Bruno ${ }^{6}$, Ashraf S. Ibrahim ${ }^{4,10}$ \& Georgios Chamilos (1) ${ }^{1,2}$
}

Correction to: Nature Communications https://doi.org/10.1038/s41467-018-05820-2; published online: 20 August 2018

The original version of this Article contained an error in the spelling of the author Emilien Etienne, which was incorrectly given as Emilien Ettiene. These errors have now been corrected in both the PDF and HTML versions of the Article.

Published online: 22 November 2018

(i) Open Access This article is licensed under a Creative Commons Attribution 4.0 International License, which permits use, sharing, adaptation, distribution and reproduction in any medium or format, as long as you give appropriate credit to the original author(s) and the source, provide a link to the Creative Commons license, and indicate if changes were made. The images or other third party material in this article are included in the article's Creative Commons license, unless indicated otherwise in a credit line to the material. If material is not included in the article's Creative Commons license and your intended use is not permitted by statutory regulation or exceeds the permitted use, you will need to obtain permission directly from the copyright holder. To view a copy of this license, visit http://creativecommons.org/licenses/by/4.0/.

(c) The Author(s) 2018

\footnotetext{
${ }^{1}$ Department of Medicine, University of Crete, Foundation for Research and Technology, 71300 Heraklion, Crete, Greece. ${ }^{2}$ Institute of Molecular Biology and Biotechnology, Foundation for Research and Technology, 71300 Heraklion, Crete, Greece. ${ }^{3}$ Laboratory of Immunobiology, Center for Clinical, Experimental Surgery, and Translational Research, Biomedical Research Foundation of the Academy of Athens, 11527 Athens, Greece. ${ }^{4}$ Division of Infectious Diseases, Los Angeles Biomedical Research Institute, Harbor-University of California Los Angeles (UCLA) Medical Center, 1124 West Carson Street, St. John's Cardiovascular Research Center, Torrance, CA 90502, USA. ${ }^{5}$ Sharjah Institute for Medical Research, College of Pharmacy, University of Sharjah, PO Box 27272Sharjah, UAE. ${ }^{6}$ Institute for Genome Sciences, University of Maryland School of Medicine, Baltimore, MD 21201, USA. ${ }^{7}$ CNRS, BIP (UMR 7281), IMM (FR 3479), Aix-Marseille Université, 31 chemin J. Aiguier, 13402 Marseille, France. ${ }^{8}$ Unité des Aspergillus, Institut Pasteur, 75015 Paris, France. 9 Department of Infectious Diseases, Infection Control, and Employee Health, The University of Texas MD Anderson Cancer Center, Houston, TX 77030, USA. ${ }^{10}$ David Geffen School of Medicine at UCLA, Los Angeles, CA 90095, USA. These authors contributed equally: Angeliki M. Andrianaki, Irene Kyrmizi. Correspondence and requests for materials should be addressed to A.S.I. (email: ibrahim@labiomed.org) or to G.C. (email: hamilos@imbb.forth.gr)
} 